\title{
DIMENSÕES DA GOVERNANÇA JUDICIAL E SUA APLICAÇÃO AO SISTEMA JUDICIAL BRASILEIRO
}

\author{
Luiz Akutsu e Tomás de Aquino Guimarães
}

JUDICIAL GOVERNANCE DIMENSIONS AND THEIR APPOINTMENT TO

THE BRAZILIAN JUDICIAL SYSTEM

\section{RESUMO}

A ADMINISTRAÇÃO DA JUSTIÇA BRASILEIRA ENFRENTA DIFICULDADES CRÔNICAS DE ACESSIBILIDADE DA POPULAÇÃO DE MENOR RENDA À JUSTIÇA, DE MOROSIDADE E DE BAIXA EFICÁCIA DAS DELIBERAÇÕES JUDICIAIS. O PRESENTE ESTUDO BUSCA CONTRIBUIR PARA O EXAME DE SOLUÇÕES PARA TAIS DIFICULDADES, TENDO COMO OBJETIVOS IDENTIFICAR DIMENSÕES RELACIONADAS AO CONCEITO DE GOVERNANÇA JUDICIAL ESTUDADAS EM PESQUISAS EMPÍRICAS RECENTES E DISCUTIR COMO TAIS DIMENSÕES PODEM INFLUENCIAR O DESEMPENHO DO SISTEMA JUDICIAL BRASILEIRO. AS SEGUINTES DIMENSÕES FORAM IDENTIFICADAS: INDEPENDÊNCIA JUDICIAL; ACCOUNTABILITY; ACESSIBILIDADE À JUSTIÇA; ESTRUTURA DO PODER JUdiCIÁRIO; RECURSOS ESTRATÉGICOS DO PODER JUDICIÁRIO; E DESEMPENHO DO SISTEMA JUDICIAL. ANTE A ESCASSEZ DE ESTUDOS EMPÍRICOS SOBRE GESTÃO DO JUDICIÁRIO EM GERAL E DO BRASIL EM PARTICULAR, FORAM FORMULADAS PROPOSTAS DE PESQUISAS PARA AVALIAR, ENTRE OUTROS ASPECTOS: (A) A INFLUÊNCIA DO DESENVOLVIMENTO DOS RECURSOS ESTRATÉGICOS NO DESEMPENHO DO POdER JUdICIÁRIO; E (B) O IMPACTO, NA DIMINUICCÃO DA CORRUPÇÃO DO SISTEMA JUDICIAL BRASILEIRO, DO AUMENTO DA INDEPENDÊNCIA JUDICIAL E DA GARANTIA DE QUE OS JUÍZES SEJAM ACCOUNTABLES PERANTE A SOCIEDADE.

\section{PALAVRAS-CHAVE}

ACCOUNTABILITY; ADMINISTRAÇÃO DA JUSTIÇA; DESEMPENHO; INDEPENDÊNCIA; GOVERNANÇA JUDICIAL.

\begin{abstract}
THE BRAZILIAN JUSTICE MANAGEMENT FACES CHRONIC DIFFICULTIES OF ACCESSIBILITY OF LOWER INCOME POPULATION TO JUSTICE, THE SLOWNESS AND LOW EFFECTIVENESS OF THE JUDICIAL DECISIONS. IN ORDER TO CONTRIBUTE TO THE ANALYSIS OF SOLUTIONS TO THESE DIFFICULTIES, THE OBJECTIVES OF THIS PAPER ARE TO IDENTIFY DIMENSIONS RELATED TO THE CONCEPT OF JUDICIAL GOVERNANCE STUDIED IN RECENT EMPIRICAL RESEARCHES, AND DISCUSS HOW THESE DIMENSIONS CAN PUSH THE PERFORMANCE OF THE BRAZILIAN JUDICIAL SYSTEM. THE FOLLOWING DIMENSIONS WERE IDENTIFIED: JUDICIAL INDEPENDENCE, ACCOUNTABILITY, ACCESSIBILITY TO JUSTICE; StRUCTURE OF THE JUDICIARY; STRATEGIC RESOURCES OF THE JUDICIARY, AND JUDICIARY'S PERFORMANCE. FACED WITH THE SCARCITY OF EMPIRICAL STUDIES ON MANAGEMENT OF THE JUDICIARY, SPECIALLY ON BRAZILIAN COURTS, RESEARCH PROPOSALS ARE MADE, INCLUDING THE FOLLOWING: (A) TO EVALUATE THE INFLUENCE OF THE DEVELOPMENT OF STRATEGIC RESOURCES IN THE PERFORMANCE OF THE JUDICIARY; AND (B) TO EVALUATE THE IMPACT OF INCREASED JUDICIAL INDEPENDENCE AND ACCOUNTABILITY ON REDUCING CORRUPTION OF THE BRAZILIAN JUDICIAL SYSTEM.
\end{abstract}

\section{KEYWORDS}

ACCOUNTABILITY; JUDICIAL MANAGEMENT; PERFORMANCE; INDEPENDENCE; JUDICIAL GOVERNANCE.

\section{INTRODUÇÃO}

A baixa acessibilidade da população de menor renda à Justiça e a morosidade e a baixa eficácia das decisões judiciais são algumas das dificuldades crônicas enfrentadas pelos 
cidadãos que buscam o sistema judicial brasileiro. Essas dificuldades podem ser minimizadas tanto com medidas mais estreitamente relacionadas à área do direito propriamente dito - como alterações na legislação processual - quanto com medidas relacionadas à administração do Judiciário. O escopo desta pesquisa relaciona-se justamente a essa última área: a governança judicial.

Embora a discussão sobre governança seja relevante e atual, o conceito não é novo. Segundo Kauffmann e Kraay (2008), há notícias de discussões sobre o tema que remontam ao ano 400 a. C., quando Kautilya, suposto ministro-chefe do rei da Índia, teria apresentado o Arthashastra, um tratado sobre a arte da governança, enfatizando a justiça, a ética e as tendências antiautocráticas. Os autores destacam que, embora o conceito tenha sido mencionado em relatos tão antigos, não há consenso acerca de uma definição sobre governança e apontam para a importância de, para analisar e interpretar esse fenômeno, se levar em conta as principais dimensões associadas às inúmeras definições do termo.

Ao revisar a literatura sobre o tema, Claessens (2006) evidencia que uma boa governança corporativa está associada a custos de capital mais baixos e a retornos mais expressivos em termos de equidade, eficiência e tratamento mais favorável aos stakeholders. Andrade e Rossetti (2009, p. 552) corroboram o argumento de Claessens (2006) destacando que "a amplitude dos impactos positivos dos princípios, dos propósitos e das práticas de boa governança é [...] uma das raras unanimidades que se estabeleceram nos últimos anos nos campos da economia, das finanças e da administração" e argumentam que o conceito de governança corporativa pode ser transposto para a gestão do Estado. Para os autores, a questão-chave do Estado não é de governabilidade, mas de governança: "enquanto a primeira é uma conquista circunstancial e geralmente efêmera do poder estabelecido, a segunda é uma conquista da sociedade, estrutural e duradoura" (Andrade e Rossetti, 2009, p. 562).

Deve-se destacar, contudo, que a governança pode existir sem governo, conforme argumenta Rosenau (2010, p. 14): “presumir a existência da governança sem um governo significa conceber funções que precisam ser executadas para dar viabilidade a qualquer sistema humano, mesmo que o sistema não tenha produzido organizações e instituições incumbidas explicitamente de exercê-las”. O autor refere-se à interação entre os Estados, num contexto de globalização econômica e de crescente interação da política mundial, o qual demanda entender como pode existir uma governança na ausência de um governo. Ao estudar o conceito de governança nesse contexto, Czempiel (2010, p. 335) concorda que o sistema internacional é um sistema de governança: "entendo 'governança' como a capacidade de fazer coisas sem a competência legal para ordenar que elas sejam feitas”.

As definições mais comuns para os termos governança corporativa e governança do Estado trazem pressupostos similares aos expostos por Rosenau (2010) e Czempiel 
(2010). Rabelo e Silveira (1999, p. 6) definem governança corporativa como "um conjunto de questões relativas aos mecanismos de controle utilizados nas grandes corporações”. A governança está relacionada, assim, tanto para o setor público quanto para o setor privado, aos mecanismos de controle nas organizações, utilizados para a consecução de seus objetivos. Em consonância com tais referências, adota-se neste trabalho a seguinte definição para o termo governança: "ferramenta analítica para compreensão dos fatores que organizam a interação dos atores, a dinâmica dos processos e as regras do jogo" (Ibanhes et al., 2007, p. 577).

Justifica-se a escolha do tema "governança judicial" em face de o estudo do sistema judicial brasileiro ter sido colocado em destaque na agenda política do país nos últimos anos, com o "Pacto de Estado em favor de um Judiciário mais rápido e republicano" (Brasil, 2004), firmado pelos presidentes dos poderes Executivo, Judiciário e Legislativo, destinado a aprimorar a gestão do sistema judicial brasileiro. Uma das premissas desse pacto é que "poucos problemas nacionais possuem tanto consenso no tocante aos diagnósticos quanto à questão judiciária” e que os principais problemas relacionados à administração da Justiça relacionam-se à morosidade das ações judiciais e à baixa eficácia de suas decisões (Brasil, 2004, p. 8). Em 2009 houve o "II pacto republicano de Estado por um sistema de Justiça mais acessível, ágil e efetivo", reiterando o compromisso de buscar soluções para os problemas relacionados à morosidade e à baixa efetividade das deliberações judiciais, tendo o novo documento destacado outro problema: a necessidade de um sistema de Justiça mais acessível, especialmente aos mais necessitados (Brasil, 2009). Além disso, são escassos os estudos relacionados com administração do Judiciário.

O estudo da área temática "governança judicial” encontra amparo também em proposta recente de $\mathrm{Ng}$ (2011), cujo estudo propõe a criação da referida disciplina, por entender que a abordagem do ponto de visto estritamente jurídico é insuficiente para a compreensão de questões que envolvem a crescente cobrança por maior accountability por parte dos inúmeros atores com interesse no funcionamento das cortes. O autor defende, assim, uma abordagem interdisciplinar para a disciplina de governança judicial, que leve em conta teorias relacionadas às ciências do direito, da política, da economia e da administração.

Assim, levando em consideração esse contexto, a presente pesquisa busca, por meio do estudo de dimensões relacionadas ao conceito de governança judicial, contribuir para o exame de soluções para melhorar o sistema judicial brasileiro e tem como objetivos identificar dimensões relacionadas ao conceito de governança judicial estudadas em pesquisas empíricas recentes e discutir como tais dimensões podem influenciar o desempenho do sistema judicial brasileiro. Além da presente introdução, este artigo está divido em quatro seções. A seção 1 traz a metodologia adotada para levantamento de dados da pesquisa. A seção 2 descreve o estado da arte 
a respeito de governança judicial e as principais conclusões da revisão teórica realizada. A revisão teórica à luz do sistema judicial brasileiro é discutida na seção 3 . Ao final, é proposta uma agenda de pesquisa e são apresentadas as considerações finais deste trabalho.

\section{Metodologia}

Quanto aos aspectos metodológicos, este estudo pode ser caracterizado como descritivo e analítico, fundamentado em literatura e em conclusões de artigos sobre o tema "governança judicial", em revisão do estado da arte de periódicos brasileiros e estrangeiros. O estudo pode ser caracterizado também como de natureza exploratória, dada a escassez de estudos sobre o tema que tratem, em especial, sobre o sistema judicial brasileiro.

Para a identificação do estado da arte sobre o tema "governança judicial", foi realizada uma busca nas seguintes bases de dados: Academic Search Premier; Cambridge Journals Online; Emerald Fulltext; JSTOR Arts \& Sciences I Collection; OECD iLibrary; Oxford Journals; Project Muse; SAGE Journals Online; ScienceDirect (Elsevier); SpringerLink (MetaPress); Wiley Online Library e Scielo. Foram utilizadas as palavras-chave judicial e governance, utilizadas simultaneamente para preenchimento do critério "assunto" nos respectivos campos dos mecanismos de busca. Em seguida, foi feita a leitura dos resumos dos textos indicados pelos mecanismos de busca, visando identificar se os artigos tinham como objeto de estudo o sistema judicial. Para os artigos em que a leitura do resumo não deixava claro o objeto de estudo, procedeu-se à análise do restante de seu conteúdo.

Entre os artigos recuperados na busca, foram selecionados aqueles que: (a) foram publicados no período de janeiro de 2005 a janeiro de 2011; (b) tratavam do tema "governança judicial"; e (c) constituíam um relato de pesquisa empírica. Esses procedimentos foram repetidos utilizando-se, simultaneamente, as palavras-chave court e governance; judicial e organisation; court e management; judiciary e governance; justice e governance, judicial e performance; court e performance; justice e performance; justice e administration; judicial e administration, bem como as palavras-chave correspondentes em português.

Foram selecionados 23 artigos empíricos, sendo quatro publicados em periódicos brasileiros e 19 em periódicos estrangeiros. Referidos artigos foram agrupados segundo as dimensões de governança judicial estudadas. Buscou-se, por meio da leitura dos respectivos títulos, resumos e palavras-chave, identificar as principais dimensões abordadas em cada artigo. Os artigos que abordaram mais de uma dimensão foram classificados na dimensão cujas conclusões foram consideradas mais relevantes. A distribuição desses artigos é apresentada no quadro 1 (ver apêndice) e descrita na seção 2, a seguir. 


\section{GOVERNANÇA JUDICIAL: DIMENSÕES IDENTIFICADAS NO ESTADO DA ARTE}

Dos 23 estudos coletados, a dimensão "desempenho do sistema judicial” é a que contém a maior proporção de artigos, com nove textos, representando 39\% do total. Em seguida, foram identificadas as seguintes dimensões: "independência judicial”, com cinco artigos (22\% do total); "accountability ${ }^{1}$ e recursos estratégicos do Poder Judiciário", com três artigos cada (13\% do total); "acessibilidade à Justiça", com dois artigos (9\% do total); por fim, "estrutura do Poder Judiciário", com um artigo (4\% do total). Apresentam-se, nas subseções 2.1 a 2.6 a seguir, as principais conclusões desses artigos relacionadas às dimensões de governança de sistemas judiciais.

\section{I DeSEMPENho do Sistema JUdicial}

Staats et al. (2005) compararam o desempenho de sistemas judiciários de dezessete países da América Latina, com base em percepção de acadêmicos e profissionais ligados ao Poder Judiciário. Os autores mediram cinco dimensões: "independência judicial”, “accountability", "eficiência”, "efetividade” e "acessibilidade à Justiça”. Os resultados do estudo evidenciaram a importância de avaliações efetivas e confiáveis do desempenho de sistemas judiciais as quais, baseadas em múltiplos critérios, permitam entender e comparar as reformas judiciais nos diversos países da América Latina, identificando-se em especial as reformas efetivas e as causas do sucesso ou do fracasso dessas reformas.

Van Montfort et al. (2005) estudaram fatores que influenciam o tempo de julgamento em cortes distritais na Holanda. Os autores partiram de duas abordagens teóricas: (a) abordagem racional: o tempo de julgamento é influenciado pelo interesse das partes em acelerar ou retardar o andamento da causa; e (b) abordagem sistêmica: o tempo de julgamento é influenciado por características gerenciais das cortes. Os resultados evidenciaram que: (a) as partes que preferem retardar a solução do litígio ficam mais satisfeitas com a duração do procedimento que as partes que têm preferência por procedimentos mais rápidos; (b) tanto a conduta dos litigantes no nível micro quanto características gerenciais das cortes distritais influenciam na duração dos procedimentos judiciais; (c) três fatores (o número de casos não julgados nas cortes distritais, a complexidade dos casos e o tempo que o réu demora para apresentar a defesa) têm influência estatística significativa na duração dos procedimentos. Desses três fatores, a pesquisa mostrou que o estoque de processos sem julgamento é uma causa importante para a demora no julgamento de recursos.

Beer (2006) analisou o sistema judicial mexicano destacando a importância de se separar o desempenho judicial em vários componentes. Fazendo remissão a estudos anteriores, destaca o estudo das dimensões "independência judicial”, "efetividade" e "acessibilidade à Justiça", argumentando que diversas forças influenciam tais dimensões. Os resultados da pesquisa indicam que: (a) estados que são mais dependentes 
de exportações têm sistemas judiciais menos efetivos e menos acessíveis; (b) o número de organizações que defendem direitos humanos em cada estado não é um bom preditor do desempenho judicial; (c) a competição política leva à maior independência judicial: estados com eleições mais competitivas gastam mais com seus judiciários; e (d) a pobreza tem um impacto negativo no comportamento das instituições judiciais: quanto maior a pobreza, maior a corrupção.

Kahan (2006) estudou fatores determinantes que levam firmas norte-americanas a escolher determinado estado como sua sede principal. Tal decisão é importante para empresas dos Estados Unidos porque, independentemente de onde a empresa conduza seus negócios, esta pode escolher como sede principal qualquer estado da federação e seguir a legislação comercial do seu domicílio. Os resultados do estudo evidenciaram que as firmas estão mais propensas a se instalarem em estados com legislação comercial que lhes oferece flexibilidade para escolher seus mecanismos de governança e em estados com sistemas judiciais de melhor qualidade.

Rosales-López (2008) estudou o desempenho de juizados de primeira instância da Espanha, buscando responder às seguintes questões: (a) por que a produção de algumas cortes é maior que a de outras? (b) as cortes podem produzir mais justiça usando os mesmos recursos? e (c) as cortes que têm maior produtividade têm um percentual maior de suas deliberações alteradas pelos tribunais? Para as duas primeiras questões, os resultados da pesquisa evidenciaram que: (a) as cortes podem produzir mais deliberações com os recursos atuais; (b) as variáveis tamanho da corte, disponibilidade de serviços de apoio e reforço de serventuários têm um efeito positivo significativo no desempenho das cortes; e (c) o rodízio de juízes tem um efeito negativo significativo no desempenho das cortes. Para a terceira questão, o estudo concluiu que obter maior produtividade e uma menor taxa de reversão das deliberações não são objetivos incompatíveis no Poder Judiciário.

Mendelski (2009) investigou a variação na qualidade administrativa e judicial da governança nos países pós-comunistas que ingressaram na Comunidade Europeia no final da década de 1990. Os resultados evidenciaram que a variação no desenvolvimento institucional não se deve somente a legados estruturais ou históricos. A variação pode ser igualmente explicada por fatores mais recentes e fatores externos, tais como o impacto das condicionalidades da Comunidade Europeia.

O estudo de Boniface e Legg (2010) discute reformas no sistema judicial australiano que buscaram adequar os custos à matéria em disputa, reduzir atrasos e reconhecer que os tribunais devem se preocupar não meramente com a justiça entre as partes em um caso particular, mas distribuir justiça a todos os seus usuários. Os autores argumentam que essa concepção estendida de justiça, que não se limita à justiça entre as partes e inclui os interesses de outros usuários de um sistema judicial, traz como pressuposto o reconhecimento de que os recursos disponíveis aos administradores da Justiça não são ilimitados. Defendem os autores que os gestores do 
sistema judicial devem ter como objetivo a justiça em termos amplos, conciliando três dimensões de uma sentença efetiva: uma decisão tempestiva, com custo adequado e justa. Ressaltam que nenhuma das dimensões pode ser maximizada de forma separada, sem considerar as demais, sob pena de inefetividade do sistema judicial: quanto maior for a precisão almejada numa sentença judicial, maiores serão os custos processuais e maior será o tempo despendido. Além disso, os recursos gastos num caso não estarão disponíveis para os demais.

Caplan (2010) destaca a ausência de pesquisas que tratem da avaliação da qualidade da atuação de juízes e advogados, na forma sugerida por Richard Posner: a “autópsia judicial”. Argumenta que algumas vantagens das autópsias praticadas pelos médicos legistas poderiam ser estendidas à avaliação de julgamentos encerrados: a autópsia permitiria identificar erros, avaliar desempenho e fornecer feedback para promover mudanças em um ensino do direito que tende a se distanciar das práticas dos tribunais. O estudo examina o desempenho de advogados e juízes norte-americanos em julgamentos de litígios contratuais e destaca que erros de juízes são tão corriqueiros como diagnósticos e prescrições de tratamentos incorretos por parte dos médicos. $\mathrm{O}$ autor propõe que futuras pesquisas sejam feitas com base em metodologia de pesquisa de ciências sociais, começando não com casos únicos ou mesmo um conjunto de casos, mas com proposições específicas a serem testadas por meio do exame de amostras representativas de casos com características semelhantes.

Chemin (2010) estudou a influência do tempo de julgamento no comportamento de firmas ao celebrarem contratos, partindo dos seguintes pressupostos: (a) incentivos a cooperar num acordo contratual podem diminuir, porque cortes mais lentas fazem com que o valor presente de possíveis punições decorrentes de desvios seja menor; (b) os incentivos a investir podem diminuir se houver uma possibilidade de comportamento pós-contratual oportunista por uma parceira após o investimento de recursos em custos irrecuperáveis; e (c) a lentidão na execução aumenta o comportamento oportunista dos tomadores de empréstimo - em contrapartida, os credores podem responder a esse comportamento estratégico reduzindo a disponibilidade de crédito. Ao estudar o impacto da reforma do Código de Processo Civil da Índia realizada em 2002, a qual simplificou os procedimentos das cortes e reduziu em cerca de 50\% o número de casos pendentes por juiz, o autor conclui que a reforma reduziu o número de violações de contrato, encorajou o investimento e facilitou o acesso aos financiamentos. As conclusões desse estudo ratificam a importância de um modelo de governança judicial que leve em consideração a avaliação do tempo de julgamento como uma das medidas da efetividade do sistema judicial.

As conclusões dos artigos relacionadas à dimensão "desempenho do sistema judicial" podem ser agrupadas em duas perspectivas. Os estudos de Staats et al. (2005), Beer (2006), Kahan (2006) e Mendelski (2009) abordaram a dimensão "desempenho dos sistemas judiciais" como um todo. Uma segunda perspectiva buscou avaliar o 
desempenho dos sistemas judiciais por meio do exame de aspectos específicos, tais como: tempo de julgamento, custos judiciais, qualidade das sentenças e produtividade das cortes judiciais (Van Montfort et al., 2005; Rosales-López, 2008; Boniface e Legg, 2010; Caplan, 2010; Chemin, 2010).

Contudo, independentemente da perspectiva utilizada, todos os estudos que avaliaram a dimensão "desempenho do sistema judicial" buscaram correlacionar os resultados do sistema como um todo ou aspectos específicos desses resultados com as demais dimensões identificadas neste estudo - "independência judicial”, "accountability”, "acessibilidade à Justiça”, “estrutura do Poder Judiciário” e "recursos estratégicos do Poder Judiciário”, apresentadas a seguir.

\subsection{INDEPENDÊNCIA JUDICIAL}

O estudo de Klerman e Mahoney (2005) buscou correlacionar mudanças significativas em fatores que afetam a dimensão "independência judicial” (aumentos de salários e mandatos de juízes) com a valorização de ativos no mercado de capitais. Ao estudarem dados relativos ao mercado de capitais inglês no século XVIII, os autores concluíram que aumentos da independência dos juízes estão correlacionados com aumentos nos valores de ativos financeiros, e vice-versa.

Peerenboom (2006) estudou a tensão entre as dimensões "independência judicial” e "accountability" dos juízes, examinando o procedimento de Supervisão Individual de Casos (ICS) da China. Por meio desse procedimento, decisões de juízes podem ser revistas em processos distintos dos recursos de apelação aos tribunais superiores. Os defensores de tal procedimento argumentam que sua implantação decorre do baixo nível de competência profissional dos juízes, da existência de corrupção judicial e da influência indesejável de autoridades locais. Os opositores argumentam que o ICS impede a independência judicial, dificulta a consolidação de cortes com maior autoridade e aumenta o conflito entre as cortes e os órgãos estatais. O autor conclui pela necessidade do ICS, enquanto problemas com a competência dos juízes e a corrupção persistirem, concluindo que a supervisão poderá ser eliminada quando tais questões forem resolvidas.

Cordis (2009) correlacionou variáveis que medem a dimensão "independência judicial” (remuneração, métodos de seleção e duração dos mandatos dos juízes) com o número de servidores condenados por atos de corrupção em estados norte-americanos e concluiu que, em geral, estados com maiores níveis de independência judicial apresentam menores níveis de corrupção per capita que estados com características opostas.

Canes-Wrone et al. (2010) estudaram a independência de juízes de supremas cortes estaduais norte-americanas que passam pelo processo de eleições confirmatórias. Concluíram que os votos desses juízes são influenciados pela opinião pública. Destacam, como uma das principais contribuições do trabalho, o fato de que os resultados obtidos contrariam o senso comum e os argumentos dos que defendem as 
eleições confirmatórias como meio de promover a independência dos juízes ante questões políticas.

Rosenbloom (2010) estudou o processo de escolha, pelo presidente da República, dos magistrados da Suprema Corte dos Estados Unidos, no tocante à lealdade desses magistrados à agenda dos presidentes que os conduziram à Suprema Corte. Os resultados indicam que os magistrados têm sido leais aos ideais e às perspectivas daqueles que os nomearam e que o poder da escolha dos magistrados da Suprema Corte é um fator relevante na política de pessoal do governo norte-americano.

Os artigos recuperados na revisão da dimensão "independência judicial” evidenciaram, também, que essa dimensão guarda estreita relação com a dimensão "accountability", cujos estudos são apresentados na subseção 2.3.

\subsection{ACCOUNTABILITY}

Oliveira (2005) estudou a influência do Judiciário brasileiro nas privatizações de empresas estatais realizadas na década de 1990. Para isso, baseou-se no conceito de judicialização da política, definido pela autora como "a utilização de procedimentos judiciais para a resolução de conflitos de ordem política, tais como controvérsias a respeito de normas, resoluções e políticas públicas em geral, adotadas/ implementadas pelos Poderes Executivo e Legislativo" (Oliveira, 2005, p. 559). Referido conceito inclui os julgamentos de ações que envolvam políticas governamentais e a utilização de procedimentos jurídicos na ordenação do mundo político e tem como pressuposto uma postura politicamente ativa dos juízes, envolvendo, assim, o controle de ações do Poder Executivo pelo Poder Judiciário. A pesquisa evidencia que nenhuma das ações conseguiu barrar a venda de uma empresa estatal e, portanto, não se reproduziu no país o fenômeno da judicialização da política.

A mesma autora (Oliveira, 2009) avaliou a influência do Poder Judiciário no federalismo brasileiro, quanto à forma pela qual o Supremo Tribunal Federal (STF) tem julgado ações diretas de inconstitucionalidade (ADIs) impetradas por estados contra a União, ou pela União contra os estados, no período de 1988 a 2002. O estudo evidenciou que as ADIs impetradas pela União contra os estados têm maiores chances de sucesso do que aquelas impetradas pelos estados contra a União. Além de aspectos relacionados ao papel do STF como árbitro dos conflitos entre unidades da Federação, o estudo de Oliveira (2009) discute a independência desse tribunal em relação ao Poder Executivo, já que seus membros são nomeados por este.

Oliveira (2009) pondera, contudo, que essa eventual subordinação não produz, necessariamente, um mau governo, assim como, em contraponto, a independência do Poder Judiciário não produziria, a priori, um bom governo, podendo inclusive gerar, no extremo, uma tirania dos juízes.

Mollah (2010) analisou o papel do Judiciário em assegurar accountability legal de servidores do governo de Bangladesh e seu impacto na governança no contexto 
daquele país. O termo "accountability legal” é definido como o "processo judicial pelo qual ações e decisões de servidores do governo podem ser submetidas a revisão judicial" (Mollah, 2010, p. 310). O estudo evidencia que o Judiciário é muito efetivo em assegurar accountability judicial, contribuindo assim para a proteção dos direitos humanos e para a boa governança; não obstante, o estudo constatou também que o Judiciário somente pode agir se a parte prejudicada por alguma autoridade impetrar uma ação judicial e apontou ainda casos em que a sentença não foi implementada pelo Poder Executivo. Tais situações tornam ineficaz a atuação do Judiciário (Mollah, 2010).

O percentual significativo de estudos que tratam das dimensões "independência judicial" (22\% do total) e "accountability" (13\% do total) evidenciam não somente a relevância dessas dimensões para os pesquisadores que estudam o Poder Judiciário, como também a relação entre as referidas dimensões e a efetividade das deliberações judiciais. A importância de um Poder Judiciário independente dos poderes Executivo e Legislativo decorre da necessidade de salvaguarda da liberdade individual dos cidadãos, que podem recorrer ao Judiciário contra abusos de autoridades de quaisquer dos três poderes. Caso a premissa da independência dos juízes e tribunais não se concretize, o desempenho do Judiciário pode ser afetado, uma vez que os juízes teriam dificuldade em proferir sentenças que contrariassem as autoridades dos demais poderes.

Colocando tal argumento em outros termos, é desejável que os juízes sejam independentes em relação àqueles que os nomearam, em relação às partes e aos demais interessados nos litígios judiciais e até mesmo em relação a pressões populares que podem levar a decisões de cunho populista. Contudo, os juízes não podem ser independentes em relação aos princípios e às normas da Constituição e em relação aos interesses do país: os juízes devem ser ao mesmo tempo independentes e accountables perante os cidadãos.

A governança do sistema judicial depende não somente das dimensões "independência judicial" e "accountability", mais especificamente relacionadas à conduta dos juízes, mas, ainda, das seguintes dimensões, relacionadas às características e circunstâncias dos órgãos do Poder Judiciário: "recursos estratégicos do Poder Judiciário", “acessibilidade à Justiça” e "estrutura do Poder Judiciário", cujos estudos encontramse apresentados nas subseções 2.4 a 2.6 , a seguir.

\subsection{Recursos estratégicos do Poder Judiciário}

Schneider (2005) investigou a relação entre a carreira de magistrados alemães e o desempenho das cortes judiciais. Foram estudadas duas variáveis de avaliação de desempenho: a taxa de confirmação de sentenças de um juiz de $1^{\circ}$ grau pelo respectivo tribunal federal e a produtividade, medida por indicadores que incluem o número de casos encerrados e o número de deliberações publicadas. A análise evidenciou que: (a) as cortes que empregam mais juízes com doutorado são mais produtivas, mas suas 
deliberações têm menor taxa de confirmação pelos respectivos tribunais federais; e (b) as cortes que empregam juízes com maior probabilidade de promoção são menos produtivas e produzem deliberações com menor taxa de confirmação.

O estudo de Rottman et al. (2007) descreve a implementação de um sistema de informações judiciais integrado, a partir do exame das abordagens alternativas de desenvolvimento de um sistema de gestão judicial em um município norte-americano de grande porte, utilizando o caso para ilustrar as forças que se contrapõem para implementar uma solução abrangente, eficiente e que integre informações em todo o estado.

Motsaathebe e Mnjama (2009) examinaram questões relativas à gestão de registros judiciais em Botswana e concluíram que no passado a gestão de registros judiciais do país recebeu pouca atenção, mas atualmente a Suprema Corte implementou medidas para automatizar a gestão dos documentos judiciais. Os autores destacaram ainda que uma gestão efetiva de registros judiciais é crucial para a administração da Justiça.

Cotejando-se os estudos coletados que trataram da dimensão "recursos estratégicos”, verifica-se que todos buscam respostas à mesma questão, colocada de forma implícita: como melhorar o desempenho de tribunais com os mesmos recursos?

Indicadores que medem tempestividade, acessibilidade, eficiência e efetividade do sistema judicial podem trazer algumas respostas a essa questão. Referidos indicadores podem ser utilizados para avaliar o desenvolvimento de recursos estratégicos do Poder Judiciário - em processos de seleção, promoção, avaliação e treinamento de juízes - e a implementação de sistemas de informação que promovam a accountability dos juízes e do Poder Judiciário. Pressupõe-se que tais indicadores serão melhores em sistemas judiciais com recursos estratégicos valiosos, raros, não substituíveis e difíceis de serem imitados, nos termos propostos por Barney (1991) para empresas em geral. A gestão adequada da dimensão "recursos estratégicos do Poder Judiciário" pode, assim, contribuir para o incremento da dimensão "acessibilidade à Justiça”, cujos estudos são apresentados na subseção 2.5, a seguir.

\subsection{Acessibilidade À Justiça}

Sinhoreto (2007) realizou observação etnográfica da gestão estatal de conflitos em Centros de Integração da Cidadania (CICs), na cidade de São Paulo. Os CICs foram implantados em decorrência de críticas ao formalismo excessivo dos rituais judiciais e buscam aproximar a linguagem e os valores dos operadores jurídicos, oriundos das classes altas, à realidade dos conflitos vividos pelos cidadãos das classes populares, e permitir acesso à Justiça fácil e satisfatório para as partes. O estudo evidenciou que a ampliação da oferta de serviços de Justiça diversificados e informais, sob o modelo da governança pelo pluralismo jurídico, expande o escopo da gestão estatal dos conflitos; contudo, tais serviços não necessariamente têm como resultado a expansão 
do Estado de Direito ou a expansão de rituais de resolução pautados na igualdade de tratamento diante das leis.

Veronese (2007) analisou dois projetos de assistência jurídica no Brasil conduzidos por tribunais, buscando entender a assunção da agenda de oferta de serviços jurídicos e sociais por tribunais em um contexto de legitimidade do Poder Judiciário no Brasil e discutir as questões políticas implicadas nesse problema em relação à sociedade civil organizada e a questão dos métodos alternativos de resolução de conflitos. O estudo conclui que existem relações complexas entre esses projetos e a sociedade civil, as quais decorrem do ambiente reformista no qual está assentado o Poder Judiciário brasileiro e geram duas possibilidades de relacionamento futuro: a primeira é colaborativa e pode aumentar as possibilidades de atuação das organizações da sociedade; a segunda é competitiva e pode significar, ao contrário, o aumento da disputa por espaços sociais. Na perspectiva do aumento da competição, as organizações mais frágeis tenderão a ser absorvidas pela atuação dos projetos sociais e jurídicos do Poder Judiciário e as entidades remanescentes colocarão em risco suas agendas independentes para se agregarem na luta por legitimidade social dos tribunais.

A literatura revisada indica que a dimensão "acessibilidade à Justiça” está relacionada não somente à dimensão "recursos estratégicos do Poder Judiciário" como também à dimensão "estrutura do Poder Judiciário”, conforme se descreve na subseção 2.6.

\subsection{Estrutura do Poder Judiciário}

Bybee e Pincock (2011) estudaram razões e argumentos de estados norte-americanos para atrair indivíduos a seu judiciário em detrimento de sistemas de Justiça locais operando fora do controle dos estados. Os autores destacaram que todas as cortes são triádicas em sua estrutura: elas existem porque duas partes engajadas num conflito buscam julgamento de uma terceira; uma instabilidade crítica ocorre nessa relação triádica quando a terceira parte favorece um dos litigantes. A resposta para esse problema seria maximizar o consenso: se ambas as partes envolvidas numa disputa podem selecionar a lei aplicável ao litígio e escolher o juiz, então o eventual perdedor será colocado numa posição em que consentiu com o julgamento em vez de ter sido obrigado a participar dele. É nesse contexto que se coloca a possibilidade de os cidadãos norte-americanos optarem por cortes locais ou estaduais: os estados somente podem "vender" suas cortes centralizadas aos potenciais litigantes se eles tiverem essa opção. O estudo descreve vantagens e desvantagens de cada uma das opções (cortes locais e cortes estaduais), mas não traz nenhuma conclusão sobre a superioridade de uma ou outra opção. Não obstante, a pesquisa contribui para a discussão do conceito de governança judicial proposto neste artigo ao destacar que as questões centrais que têm sido divulgadas pelas cortes estaduais para atrair indivíduos ao seu judiciário se referem à afirmação de que tais cortes "são mais eficientes 
e promovem maior equidade que as cortes locais" e, ainda, que as sentenças das cortes locais são incompreensíveis (Bybee e Pincock, 2011, p. 23).

O estado da arte identificado indica que as dimensões "acessibilidade à Justiça” e "estrutura do Poder Judiciário" estão estreitamente relacionadas entre si, uma vez que a acessibilidade depende não somente da tempestividade da prestação jurisdicional, como também da gama de serviços judiciais ofertados, os quais dependem da estrutura e das competências atribuídas ao Poder Judiciário. Estudos que avaliem o impacto na qualidade dos serviços judiciais decorrente das mudanças legislativas que autorizaram a criação dos juizados e do Conselho Nacional de Justiça (Ribeiro, 2008) poderão trazer contribuições para a compreensão dos indicadores relacionados à acessibilidade à Justiça e da relação dessa dimensão com a dimensão "estrutura do Poder Judiciário”.

Além de eventuais mudanças na estrutura do Poder Judiciário, a melhoria de indicadores relacionados à dimensão “acessibilidade à Justiça” depende de outros fatores, tais como o equilíbrio entre o número de conflitos que surgem na sociedade e da capacidade do sistema judicial de julgar tais conflitos. Os dois estudos coletados nesta revisão tratam de um aspecto desse equilíbrio: a ampliação da oferta de serviços judiciais estatais. A ampliação da oferta de serviços de Justiça pode facilitar o acesso dos cidadãos às varas judiciais, conforme evidenciaram os estudos de Sinhoreto (2007) e Veronese (2007). Contudo, referida ampliação de serviços oferecidos pelos tribunais deve ser conduzida com cautela, conforme destacou Veronese (2007), uma vez que essas inovações, embora ampliem as possibilidades de acesso à Justiça, podem trazer consequências indesejáveis, como o aumento da disputa por espaços sociais.

A ampliação do acesso à Justiça, no sistema judicial brasileiro, não está limitado à Justiça enquanto instituição estatal. Mascarenhas (2009) destaca que no sistema judicial brasileiro existem dois mecanismos de solução extrajudicial de conflitos: a autocomposição e a arbitragem. Muito embora tais mecanismos de solução extrajudicial de conflitos não sejam acessíveis às camadas mais pobres da população, pode-se pressupor que a ampliação do uso da autocomposição e da arbitragem poderá também trazer benefícios aos mais necessitados, uma vez que parte dos litígios não mais será submetida ao Poder Judiciário, diminuindo a demanda a esse poder.

Além das três possibilidades mencionadas - ampliação do uso de mecanismos extrajudiciais; mudanças na estrutura do Poder Judiciário e ampliação da oferta de serviços de Justiça -, a melhoria da acessibilidade à Justiça está relacionada ao desafio de obter melhor desempenho com os mesmos recursos disponíveis. Esse desafio remete-nos ao objetivo central deste trabalho: discutir como as dimensões identificadas na revisão de literatura podem influenciar o desempenho do sistema judicial brasileiro. A seção 3, a seguir, busca contextualizar, à luz da realidade brasileira, a discussão sobre as dimensões que influenciam a governança dos sistemas judiciais. 


\section{DiscuSSÃo DA REVISÃo TEÓRICA À LUZ DO SISTEMA JUDICIAL BRASILEIRO}

Os traços característicos do sistema judicial brasileiro foram detalhados por Ribeiro (2008) em artigo que teve como objetivo discutir em que medida a Emenda Constitucional $n^{\circ} 45$ (Brasil, 2011a) pode alterar o acesso à Justiça por meio da modificação de normas relativas ao funcionamento do Judiciário. A autora relata que, em face da influência da colonização portuguesa, no Judiciário brasileiro ocorre a distinção “entre o 'país formal', cuja existência se verifica na constituição e nos códigos legais, e o 'país real', que segue alheio dos direitos preconizados pelas leis" (Ribeiro, 2008, p. 467).

Para Ribeiro (2008), a partir da década de 1990, várias mudanças legislativas como a criação dos Juizados Especiais Cíveis e Criminais, a publicação da Emenda Constitucional $n^{\circ} 22$ e da Emenda Constitucional $n^{\circ} 45$ e a criação dos Juizados de Violência Doméstica e Familiar - tiveram como finalidade dotar o sistema judicial brasileiro de requisitos que lhe permitissem atuar de maneira mais ágil, menos complexa e mais transparente. Dessas mudanças, a mais relevante, segundo a autora, foi a Emenda Constitucional $n^{\circ} 45$, que procurou não apenas ampliar, mas, ainda, consolidar os processos de reforma já iniciados, por meio dos seguintes objetivos:

(i) razoável duração do processo; (ii) proporcionalidade entre o número de juízes na unidade jurisdicional e a efetiva demanda judicial e a respectiva população; (iii) funcionamento ininterrupto da atividade jurisdicional; (iv) distribuição imediata dos processos em todos os graus de jurisdição; e (v) criação do Conselho Nacional de Justiça (Ribeiro, 2008, p. 469-470).

Partindo-se do pressuposto de que as mudanças legislativas enumeradas pela autora são relevantes e necessárias, mas dependem de implementação para se tornarem efetivas, o contexto de reforma do sistema judicial brasileiro retratado por Ribeiro (2008) torna relevante a discussão do papel da administração da Justiça para que os objetivos almejados pela Emenda Constitucional n ${ }^{\circ} 45$ sejam alcançados. No sistema judicial brasileiro, tais mudanças dependem não somente da administração do Poder Judiciário como também dos demais poderes da República, conforme evidenciam o "Pacto de Estado em favor de um Judiciário mais rápido e republicano" (Brasil, 2004) e o "II pacto republicano de Estado por um sistema de Justiça mais acessível, ágil e efetivo" (Brasil, 2009).

Dessa forma, trazendo as questões colocadas na agenda política dos três poderes da República para o contexto do presente estudo, cabe discutir como as dimensões relacionadas ao conceito de governança judicial, identificadas nesta pesquisa, aplicáveis a contextos específicos relacionados a cada um dos estudos empíricos conduzidos em diversos países, podem influenciar a efetividade da governança do sistema judicial brasileiro. 
Do estudo dessas dimensões, sobressai que a efetividade da governança judicial depende do equilíbrio entre as dimensões "independência do Poder Judiciário" e "accountability", uma vez que a qualidade da prestação jurisdicional depende da independência dos juízes; não obstante, a independência, sem a accountability, pode levar à judicialização do poder político. Ao estudar a evolução do sistema judicial brasileiro após a Constituição de 1988, Santiso (2003) destaca que o desafio, para o Brasil, reside em fortalecer a accountability do Judiciário perante a sociedade e perante o sistema político do país, uma vez que, paradoxalmente, a questão que deve ser posta para o Judiciário brasileiro envolve avaliar não se esse poder é suficientemente independente, mas sim se ele se tornou excessivamente independente.

A agenda de pesquisa proposta na seção 4 a seguir propõe discutir como as dimensões identificadas neste estudo podem influenciar a governança do sistema judicial brasileiro. Referida agenda foi formulada pressupondo-se que os fatores que influenciam a acessibilidade e o desempenho dos sistemas judiciais de outros países também influenciam a acessibilidade e o desempenho do sistema judicial brasileiro.

\section{CONSIDERAÇÕES FINAIS E AGENDA DE PESQUISA}

Neste artigo foram identificadas as principais dimensões relacionadas ao conceito de governança judicial estudadas em pesquisas empíricas recentes. Pela discussão da influência dessas dimensões na governança do sistema judicial brasileiro, constatou-se a escassez de estudos empíricos que corroborem, para o sistema judicial brasileiro, as conclusões dos estudos realizados em outros países.

A proposição dessa agenda de pesquisa justifica-se ainda em face do pequeno número de grupos de pesquisa tratando do tema. De acordo com dados disponíveis no sítio do Conselho Nacional de Desenvolvimento Científico e Tecnológico (CNPq) (Brasil, 2011b), existem 51 grupos de pesquisa cadastrados para o tema "Poder Judiciário". Destes, somente quatro grupos são da área de administração.

O pequeno número de grupos de pesquisa que estuda a administração do Poder Judiciário foi refletido na escassa literatura produzida no Brasil sobre o tema: apenas quatro dos 23 artigos coletados na revisão bibliográfica foram publicados em periódicos brasileiros. Dessa lacuna de pesquisa sobre o tema sobressai a ausência de trabalhos empíricos que avaliem o desempenho do sistema judicial brasileiro e identifiquem as principais causas tanto da morosidade e da baixa efetividade das deliberações judiciais quanto da dificuldade de acesso da população de menor renda à Justiça. As investigações empíricas poderão trazer contribuições teóricas e de cunho prático, tais como sugestões para os atores interessados no aperfeiçoamento do Poder Judiciário brasileiro.

Assim, considerando-se o contexto do sistema judicial brasileiro em face das conclusões trazidas por artigos coletados na revisão de literatura, formulam-se as propostas de pesquisa enumeradas a seguir. 
Uma primeira proposta de pesquisa poderia avaliar a relação entre as dimensões relacionadas à governança judicial identificadas neste estudo e o desempenho do sistema judicial brasileiro, pressupondo-se que o desempenho do sistema judicial brasileiro é função da independência judicial, da accountability, da acessibilidade à Justiça, da estrutura do Poder Judiciário e de recursos estratégicos do Poder Judiciário. Essa pesquisa permitiria, por meio de uma visão global do referido sistema, aprofundar a relação entre as dimensões identificadas neste estudo e a governança do sistema judicial brasileiro.

Para examinar aspectos mais específicos que podem influenciar a efetividade do sistema judicial brasileiro, propõe-se que uma segunda pesquisa avalie a influência do desenvolvimento dos recursos estratégicos do Poder Judiciário sobre as variáveis da dimensão "desempenho do Sistema Judicial” relacionadas a tempo de julgamento, custo processual e qualidade da sentença, com as seguintes premissas: (a) a avaliação do desempenho do sistema judicial brasileiro deve levar em conta, simultaneamente, as variáveis tempo de julgamento, custo processual e qualidade da sentença; e (b) o desenvolvimento de recursos estratégicos do Poder Judiciário está associado à melhoria de processos de seleção, promoção, avaliação e treinamento de juízes e à implementação de sistemas de informação que supram juízes, partes litigantes e a sociedade com informações precisas e tempestivas.

Propõe-se que uma terceira pesquisa explore a busca de equilíbrio entre as dimensões "independência judicial” e "accountability". Essa pesquisa teria como objetivo avaliar o impacto do aumento da independência judicial e da garantia de que os juízes sejam accountables perante a sociedade na diminuição da corrupção do sistema judicial brasileiro, partindo-se dos seguintes pressupostos: (a) o aumento da independência judicial é uma condição necessária, mas não suficiente, para a diminuição da corrupção; (b) para que a corrupção diminua, é necessário que os juízes motivem suas decisões (sejam accountables); e (c) uma vez assegurada a accountability dos juízes, níveis mais altos de independência judicial estarão correlacionados a níveis mais baixos de corrupção.

Uma quarta pesquisa poderia identificar os principais fatores que influenciam a acessibilidade ao sistema judicial brasileiro, pressupondo que a melhoria da acessibilidade a esse sistema é função: (a) do equilíbrio entre o número de litígios que são submetidos ao Poder Judiciário e a capacidade do sistema judicial de julgar tais conflitos; (b) da ampliação de mecanismos de solução extrajudicial de conflitos (por exemplo, autocomposição e arbitragem); (c) de alterações na estrutura do Poder Judiciário; (d) da ampliação da oferta de serviços de Justiça diversificados; e (e) do desenvolvimento de recursos estratégicos do Poder Judiciário.

Embora as pesquisas propostas tenham tomado como referência o sistema judicial brasileiro como um todo, as relações identificadas entre as principais dimensões da governança judicial podem ser investigadas em estudos que tenham como objeto órgãos específicos do Judiciário brasileiro, tais como tribunais estaduais ou federais. Pesquisas que tenham como objetivo comparar tribunais com desempenho abaixo da 
média nacional a tribunais com desempenho acima dessa média poderão enriquecer a discussão sobre os fatores que determinam a morosidade e a baixa efetividade das deliberações judiciais.

Por fim, dada a importância das dimensões "independência judicial" e "accountability" na efetividade dos mecanismos de governança dos sistemas judiciais - e considerando-se o mandato atribuído pela Constituição ao Conselho Nacional de Justiça (CNJ), criado pela Emenda Constitucional n ${ }^{\circ} 45$ para, entre outros objetivos, fortalecer tais dimensões mediante o controle da atuação administrativa e financeira do Poder Judiciário e do cumprimento dos deveres funcionais dos juízes (Brasil, 2011a) -, sugere-se pesquisar, também, a contribuição do CNJ para assegurar a efetividade da governança do sistema judicial brasileiro.

: ARTIGO APROVADO (01/06/2012) : RECEBIDO EM 26/04/2011

\section{NOTAS}

1 Adota-se neste artigo a seguinte definição de Pinho e Sacramento (2009, p. 1348) para o termo accountability: “... não existe um termo único em português que defina a palavra accountability, havendo que trabalhar com uma forma composta. Buscando uma síntese, accountability encerra a responsabilidade, a obrigação e a responsabilização de quem ocupa um cargo em prestar contas segundo os parâmetros da lei, estando envolvida a possibilidade de ônus, o que seria a pena para o não cumprimento dessa diretiva."

\section{REFERÊNCIAS BIBLIOGRÁFICAS}

ANDRADE, A; ROSSETTI, J. P. Governança corporativa: fundamentos, desenvolvimento e tendências. 4. ed. São Paulo: Atlas, 2009.

BARNEY, J. Firm resources and competitive advantage. Journal of Management, v. 7, n. 1. p. 99-120, 1991. BEER, C. C. Judicial performance and the rule of law in the Mexican states. Latin American Politics \& Society, Miami, v. 48, n. 3, p. 33-61, 2006.

BONIFACE, D.; LEGG, M. Cost, delay and justice: the High Court of Australia recognizes the importance of case management in civil litigation - Aon Risk Services Australia Limited vs Australian National University. Common Law World Review, v. 39, p. 157-180, 2010.

BRASIL. Pacto de Estado em favor de um Judiciário mais rápido e republicano. Diário Oficial da União. Brasília, 16 dez. 2004. n. 241, seção 1, p. 8-9.

. II pacto republicano de Estado por um sistema de Justiça mais acessível, ágil e efetivo. Diário

Oficial da União, Brasília, 26 maio 2009. n. 98, seção 1, p. 1-2.

. Constituição da República Federativa do Brasil de 1988. Disponível em:

<http://www.planalto.gov.br>. Acesso em: 23 jan. 2011. 
. Emenda Constitucional 45, de 30 de dezembro de 2004. Disponível em:

<http://www.planalto.gov.br>. Acesso em: 23 jan. 2011.

. Conselho Nacional de Desenvolvimento Científico e Tecnológico (CNPq). Disponível em:

<http://dgp.cnpq.br/buscaoperacional>. Acesso em: 2 fev. 2011.

BYBEE, K.; PINCOCK, H. Efficient, fair, and incomprehensible: how the State "sells" its Judiciary. Law \& Policy, University of Denver, Colorado, v. 33, n. 1, p. 1-26, Jan. 2011.

CANES-WRONE, B.; CLARK, T. S.; PARK, J. K. Judicial independence and retention elections. Journal of Law, Economics, and Organization, p. 1-24, Sep. 2010.

CAPLAN, G. Legal autopsies: assessing the performance of judges and lawyers through the window of leading contract cases. Albany Law Review, Albany, v. 73, n. 1, p. 1-54, 2010.

CHEMIN, M. Does court speed shape economic activity? Evidence from a court reform in India. The Journal of Law, Economics, \& Organization, p. 1-26, Nov. 2010.

CLAESSENS, S. Corporate governance and development. The World Bank Research Observer, v. 21, n. 1, Spring 2006.

CORDIS, A. Judicial checks on corruption in the United States. Economics of Governance, v. 10, n. 4, p. 375-401, 2009.

CZEMPIEL, Ernst-Otto. Governança e democratização. In: ROSENAU, James; CZEMPIEL, Ernst-Otto. Governança sem governo: ordem e transformação na política mundial. Brasília: Editora Universidade de Brasília, p. 335-362, 2000.

EISENHARDT, K. M. Agency theory: an assessment and review. Academy of Management Review, v. 14, n. 1, p. 57-74, 1989.

IBANHES, Lauro César et al. Governança e regulação na saúde: desafios para a gestão na região metropolitana de São Paulo, Brasil. Cadernos de Saúde Pública, Rio de Janeiro, v. 23, n. 3, p. 575-584, 2007. KAHAN, M. The demand for corporate law: statutory flexibility, judicial quality, or takeover protection? The Journal of Law, Economics, \& Organization, v. 22, n. 2, p. 340-365, 2006.

KAUFMANN, D; KRAAY, A. Governance indicators: where are we, where should we be going? The World Bank Research Observer, v. 23, n. 1, p. 1-30, 2008.

KLERMAN, Daniel. M.; MAHONEY, Paul. G. The value of judicial independence: evidence from eighteenth century England. American Law and Economics Review, Oxford, v. 7, n. 1, p. 1-27, 2005. MASCARENHAS, A. C. F. Autonomia privada e autocomposição extrajudicial dos litígios. 2009. 174 fl. Dissertação (Mestrado em Direito) - Faculdade de Direito da Universidade Federal da Bahia, Salvador, 2009.

MENDELSKI, M. The Impact of EU on governance reforms in post-communist Europe: a comparison between first and second-wave candidates. Romanian Journal of Political Science, v. 9, n. 2, p. 42-64, 2009.

MOLLAH, M. A. Does the Judiciary matter for accountability of administration in Bangladesh? International Journal of Law and Management, v. 52, n. 4, p. 309-331, 2010.

MOTSAATHEBE, L.; MNJAMA, N. The management of High Court Records in Botswana. Records Management Journal, v. 19, n. 3, p. 173-189, 2009.

NG, G. Y. A discipline of judicial governance? Utrecht Law Review, v. 7, n. 1, p. 102-116, 2011.

OLIVEIRA, Vanessa Elias de. Judiciário e privatizações no Brasil: existe uma judicialização da política? Dados, Rio de Janeiro, v. 48, n. 3, p. 559-587, 2005.

- Poder Judiciário: árbitro dos conflitos constitucionais entre Estados e União. Lua Nova, São

Paulo, n. 78, p. 223-250, 2009.

PEERENBOOM, Randall. Judicial independence and judicial accountability: an empirical study of individual case supervision. The China Journal, n. 55, p. 67-92, Jan. 2006.

PINHO, J. A. G.; SACRAMENTO, A. R. S. Accountability: já podemos traduzi-la para o português? Revista de Administração Pública, Rio de Janeiro, v. 43, n. 6, p. 1343-1368, 2009.

RABELO, F.; SILVEIRA, J. M. Estruturas de governança e governança corporativa: avançando na direção da integração entre as dimensões competitivas e financeiras. Campinas: IE/Unicamp, 1999. RIBEIRO, L. A Emenda Constitucional 45 e o acesso à Justiça. Revista Direito GV, São Paulo, v. 4, n. 2, p. 465-492, 2008.

ROSALES-LÓPEZ, V. Economics of court performance: an empirical analysis. European Journal of Law and Economics, Maastricht, v. 25, p. 231-251, 2008.

ROSENAU, James. Governança, ordem e transformação na política mundial. In: ROSENAU, James; CZEMPIEL, Ernst-Otto. Governança sem governo: ordem e transformação na política mundial. Brasília: Editora Universidade de Brasília, p. 11-46, 2000.

ROSENBLOOM, D. George W. Bush, the Supreme Court, and the pursuit of "Big Government Conservatism" 
in Federal personnel management. Review of Public Personnel Administration, v. 30, n. 4. p. 467-485, 2010. ROTTMAN, J. W.; SMITH, L. D.; LONG, D. A. Implementing judicial management systems within an integrated Justice information framework: a case study on information systems development in the public sector. The American Review of Public Administration, v. 37, n. 4, p. 436-457, Dec. 2007.

SANTISO, C. Economic reform and judicial governance in Brazil: balancing independence with accountability. Democratization, v. 10, n. 4, p. 161-180, Nov. 2003.

SCHNEIDER, Martin R. Judicial career incentives and court performance: an empirical study of the German Labour Courts of Appeal. European Journal of Law and Economics, Maastricht, v. 20, n. 2, p. 127-144, 2005.

SINHORETO, J. Reforma da Justiça (estudo de caso). Tempo Social, São Paulo, v. 19, n. 2, p. 157-177, 2007. STAATS, Joseph L.; BOWLER, Shaun; HISKEY, Jonathan. T. Measuring judicial performance in Latin America. Latin American Politics \& Society, Miami, v. 47, n. 4, p. 77-106, 2005.

VAN MONTFORT, A. J. G. M.; JONG, P. O.; HERWEIJER, M.; MARSEILLE, A. T. The sooner the better: management of time in district courts. International Journal of the Sociology, Portsmouth, v. 33, p. 35-51, 2005. VERONESE, A. Projetos judiciários de acesso à Justiça: entre assistência social e serviços legais. Revista Direito GV, São Paulo, v. 3, n. 1, p. 13-34, 2007.

\section{APÊNDICE}

Quadro 1: Artigos EMPíricos SObre gOVERNANÇA JUDICIAL PUbliCAdOS ENTRE JAN/2005 E JAN/20II

\begin{tabular}{|c|c|c|c|}
\hline Dimensão & Percentual & TEMAS ABORDADOS NO(s) ESTUdo(s) & N. \\
\hline \multirow{4}{*}{$\begin{array}{l}\text { DESEMPENHO DO } \\
\text { SISTEMA JUDICIAL }\end{array}$} & \multirow[b]{4}{*}{$39 \%$} & CUSTO, TEMPESTIVIDADE E QUALIDADE DAS SENTENÇAS & 2 \\
\hline & & TEMPO DE JULGAMENTO & 2 \\
\hline & & QUALIDADE DA GOVERNANÇA E DOS SISTEMAS JUDICIAIS & 2 \\
\hline & & DESEMPENHO DO JUDICIÁRIO - FATORES DETERMINANTES & 3 \\
\hline \multirow[b]{4}{*}{ INDEPENDÊNCIA JUDICIAL } & \multirow[b]{4}{*}{$22 \%$} & PROCESSO dE SELEC̣ÃO DOS MAGISTRADOS & 1 \\
\hline & & ELEIC̣ÕES CONFIRMATÓRIAS PARA REELEIC̣ÃO DE JUÍZES & 1 \\
\hline & & INDEPENDÊNCIA E CORRUPC̣ÃO DE JUÍZES & 2 \\
\hline & & IMPACTO DA INDEPENDÊNCIA JUDICIAL NO MERCADO DE CAPITAIS & 1 \\
\hline ACCOUNTABILITY & $13 \%$ & $\begin{array}{l}\text { IMPACTO DAS DECISÕES JUDICIAIS NA ACCOUNTABILITY DOS } \\
\text { GESTORES PÚBLICOS E EM OUTROS PODERES }\end{array}$ & 3 \\
\hline \multirow{2}{*}{$\begin{array}{l}\text { RECURSOS ESTRATÉGICOS } \\
\text { DO PODER JUDICIÁRIO }\end{array}$} & \multirow[b]{2}{*}{$13 \%$} & GESTÃO DE DOCUMENTOS E INFORMAÇÕES JUDICIAIS & 2 \\
\hline & & CARREIRA DOS MAGISTRADOS & 1 \\
\hline \multirow[b]{2}{*}{ ACESSIBILIDADE À JUSTIÇA } & \multirow[b]{2}{*}{$9 \%$} & OFERTA DE SERVIÇOS JUDICIAIS COM RITUAIS SIMPLIFICADOS & 1 \\
\hline & & NOVAS FORMAS DE RESOLUÇÃO DE CONFLITOS & 1 \\
\hline $\begin{array}{l}\text { ESTRUTURA DO } \\
\text { PODER JUDICIÁRIO }\end{array}$ & $4 \%$ & DISTRIBUIC̣ĀO DE COMPETÊNCIAS ENTRE JUÍZES E TRIBUNAIS & 1 \\
\hline TOTAL & $100 \%$ & & 23 \\
\hline
\end{tabular}


202 : DIMENSÕES DA GOVERNANÇA JUDICIAL E SUA APLICAC̣ÃO AO SISTEMA JUDICIAL BRASILEIRO

\section{Luiz Akutsu}

SQS 210, Bloco A, apartamento 503 CEP: 70273-010 Brasília - DF - Brasil luiz_akutsuayahoo.com.br

UnB - PPGA Instituto Central de Ciências, Ala Norte Subsolo, Módulo 25 70910-900 Brasília - DF - Brasil tomas.aquino.guimaraeslagmail.com
DOUTORANDO EM AdMINISTRAÇÃo PELA Universidade de Brasília (UnB) Mestre em AdMinistraÇão PELA Universidade FEDERAL dA BAHIA (UFBA) BACHAREL EM DiREITO PELA UNIVERSIDADE DE BRASília (UNB)

ENGENHEIRO MECÂNICO-AERONÁUTICO PELO Instituto TECnOlógico da Aeronáutica (ITA)

\section{Tomás de Aquino Guimarães} Professor titular da Universidade de Brasília (UnB) Doutor em Sociologia pela Universidade de São Paulo (USP), COM PERÍODO COMO STUDY FELLOW NO SCIENCE AND TECHNOLOGY Policy Research (SPRU), ReIno Unido

MESTRE EM AdMINISTRAÇÃO PELA FundaÇÃO GETULIO VARGAS (FGV)

Graduado em Administração PELA AsSOCIAC̣Ão dE Ensino Unificado do Distrito Federal 